\title{
Monoclonal Microbial EDP1503
}

National Cancer Institute

\section{Source}

National Cancer Institute. Monoclonal Microbial EDP1503. NCI Thesaurus. Code C155907.

An orally available preparation derived from a single clone of Bifidobacterium spp. with potential immunomodulatory and antineoplastic activities. Upon oral administration, monoclonal microbial EDP1503 colonizes the gut and may, through a not yet fully elucidated mechanism, promote the activation of dendritic cells (DCs), and enhance the induction and infiltration of cytotoxic T-lymphocytes (CTLS) in the tumor microenvironment (TME). Bifidobacterium is a genus of anaerobic, Gram-positive bacteria, with some species being a commensal part of the human gastrointestinal tract and vaginal flora. 